\title{
High Dynamic Range Digital Imaging of Spacecraft
}

\author{
Brian Karr $^{1,2}$, Kurt Debattista ${ }^{2}$, Alan Chalmers ${ }^{2}$ \\ ${ }^{1}$ Advanced Imaging Lab, Kennedy Space Center, Florida \\ ${ }^{2}$ University of Warwick, UK
}

\begin{abstract}
The ability to capture engineering imagery with a wide degree of dynamic range during rocket launches is critical for post launch processing and analysis [USC03, NNC86]. Rocket launches often present an extreme range of lightness, particularly during night launches. Night launches present a two-fold problem: capturing detail of the vehicle and scene that is masked by darkness, while also capturing detail in the engine plume.
\end{abstract}

Categories and Subject Descriptors (according to ACM CCS): I.4.1 [IMAGE PROCESSING AND COMPUTER VISION]: Digitization and Image Capture - Quantization

\section{Introduction}

Figures 1 and 2 illustrate a debris event as displayed in an 8 bit representation during a spacecraft night mission. Figure 1 captures debris to the left and above the vehicle in the night sky, illuminated by the engine plume. Figure 2 includes debris in front of the engine plume.

The exposure was set to capture detail in the flame, while the limitation in dynamic range results in little to no observable detail in the vehicle area. While the debris can be observed in and near the plume area, there is a loss of useful visual information as to the origination point from the vehicle, how the debris was generated, and the remaining state of the vehicle. Detail of the debris itself is also reduced as a result of the limited dynamic range, amongst other factors such as image resolution and optical system sharpness.

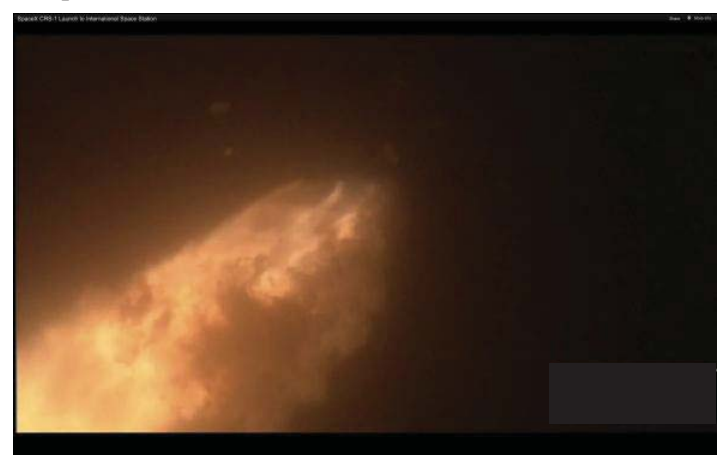

Figure 1: Engine Debris Upper Left of Plume during Night Mission

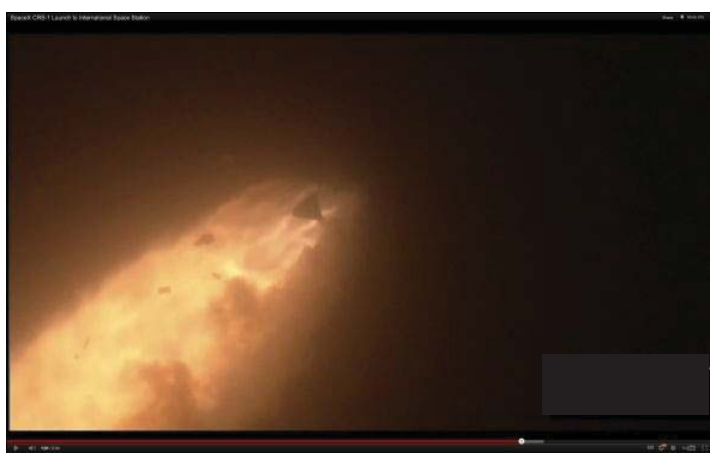

Figure 2: Engine Debris in Front of Plume during Night Mission

\section{Space Shuttle Era Engineering Imagery}

During the Space Shuttle Program, Engineering Imagery was primarily collected through the use of $16 \mathrm{~mm}$ and $35 \mathrm{~mm}$ high speed film cameras. Testing of HDR digital image capture began in 2009, in preparation for an eventual film to digital transition.

\subsection{Initial Attempt}

Two 8 bit HD1100 2/3 inch sensor industrial cameras with similar fields of view during STS-129 [SHK*09] (See Figures 3 and 4). 


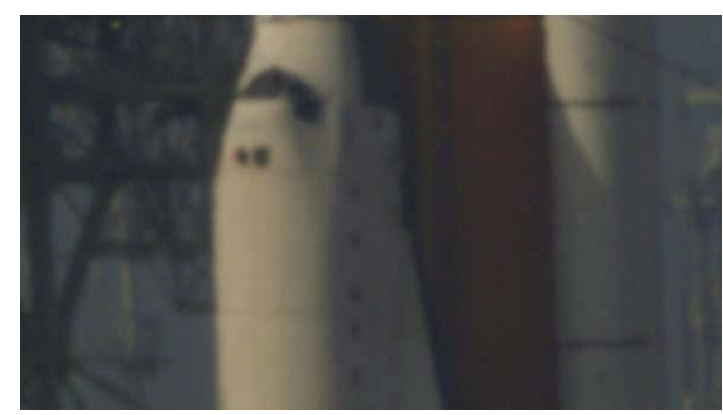

Figure 3: HD1100 Cam A (1/60 exposure)

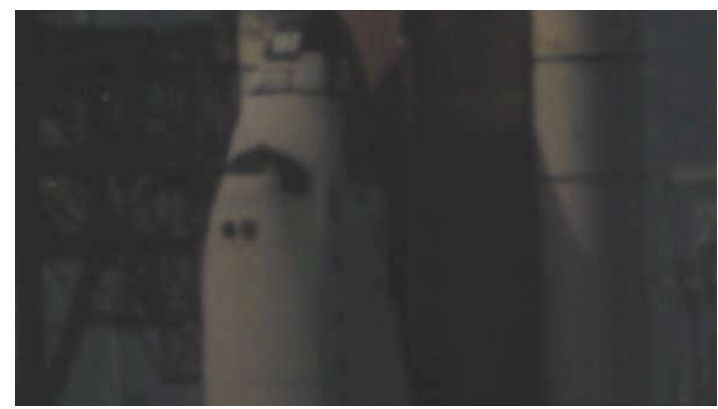

Figure 4: HD1100 Cam B (1/300 exposure)

\subsection{RED ONE M}

The cameras were configured for STS-131 [SHK*10a] to acquire imagery of the launch from five camera sites around the pad perimeter (see Figures 5 and 6). Deployed in pairs to each site, the cameras provided imagery not only for HDR testing purposes, but also to generate stereoscopic $3 \mathrm{D}$ image sets.

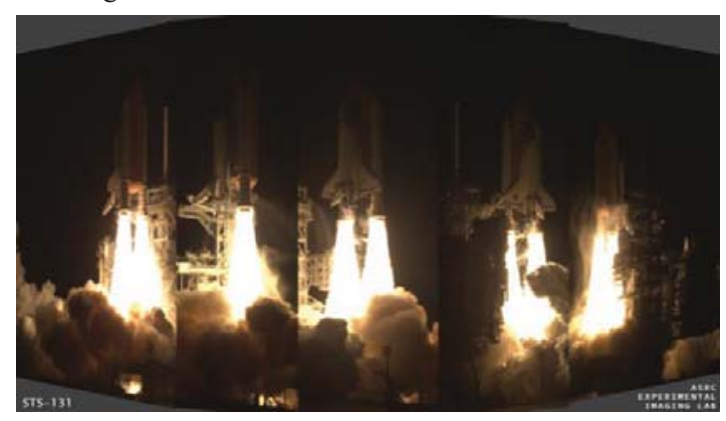

Figure 5: RED ONE Composite of 5 Camera Sites

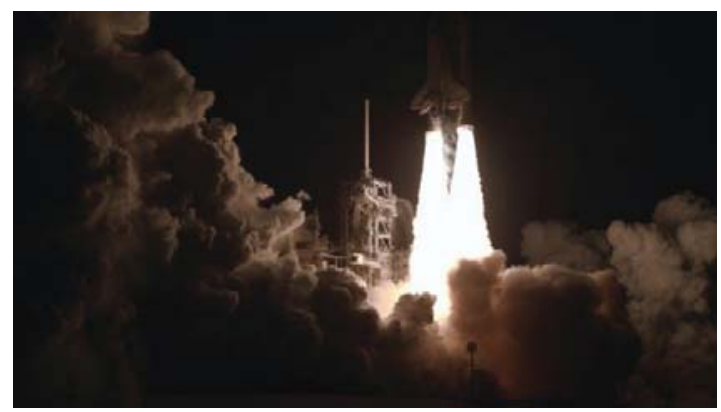

Figure 6: RED ONE Camera Site 3 Single Frame
The RED ONE M experiment was successful in illustrating the capability of single exposure digital imagers at that time. Lab testing has shown that the RED ONE M has a dynamic range of 10.4 stops with 0.5 stop RMS noise, Log mode.

\subsection{Two HD1100 High Definition Cameras}

These cameras with matched 80in focal length Meade telescopes were again used for a dual imager HDR experiment during STS-132 [CHK*10b].

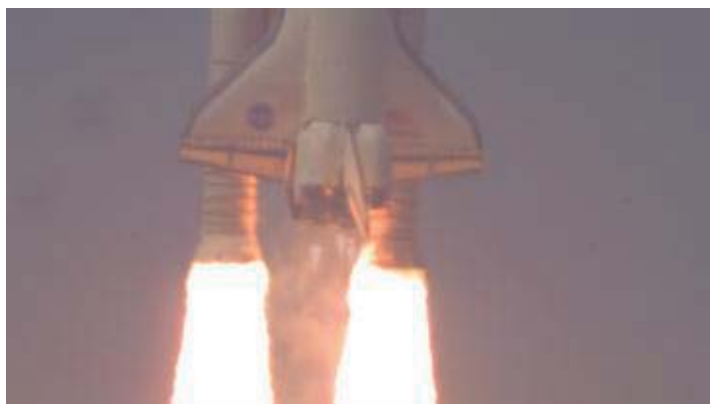

Figure 7: HD1100 Cam A (f/10 exposure)

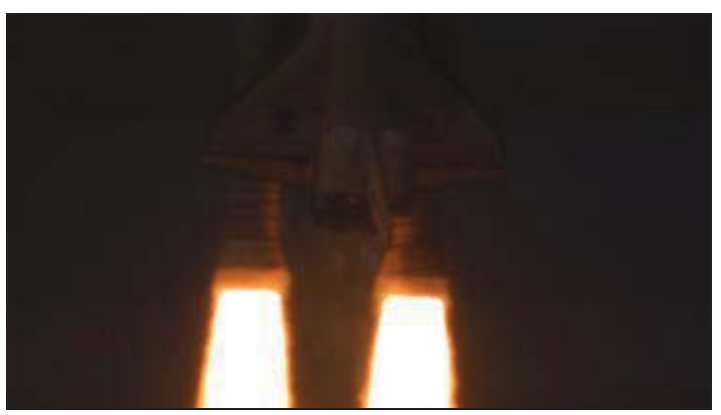

Figure 8: HD1100 Cam A (f/20 exposure)

The HDR image generated from the HD1100 exhibited some detail over a greater range than did imagery from either camera individually (see Figures 7 and 8).

\section{STS-135 Final Space Shuttle Flight}

A number of digital images were acquired to capture the final Space Shuttle flight of STS-135, including the Phantom HD Gold HSD, RED ONE M, RED EPIC, Cooke Dimax HSD, Photron SA1 and SA2 HSD, and ARRI Alexa [HKPO*11].

\subsection{RED ONE M 4K}

A RED One $4 \mathrm{~K}$ camera was deployed to the infield location near camera site 4 as shown in Figures 9 and 10. A 25 $\mathrm{mm}$ RED lens was used for the wide angle field of view. The resulting imagery was as expected, similar in dynamic range response to previous tests. 


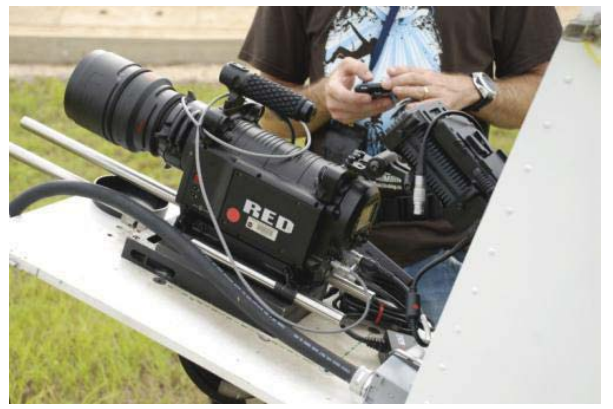

Figure 9: RED ONE M $4 K$ Setup

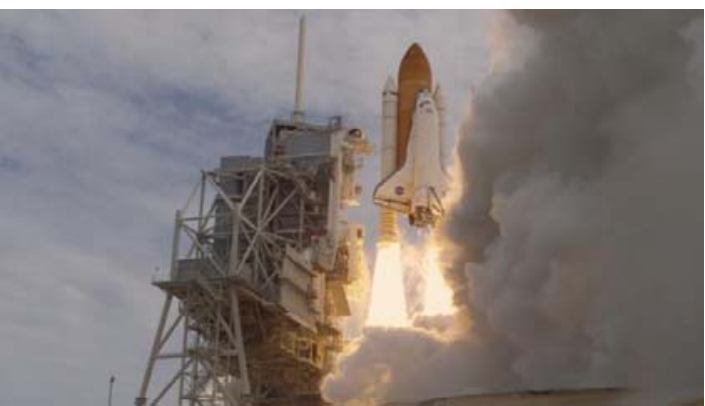

Figure 10: RED ONE M 4K Sample Frame

\subsection{ARRI Alexa}

Lab tested for 13.9 stops at a 0.5 stop RMS noise, Log mode (Figures 11 and 12).

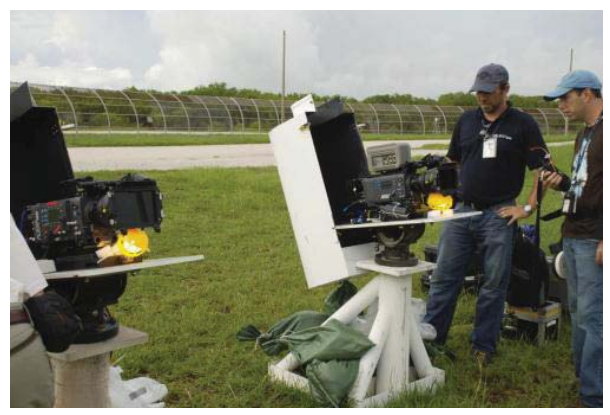

Figure 11: ARRI Alexa Setup

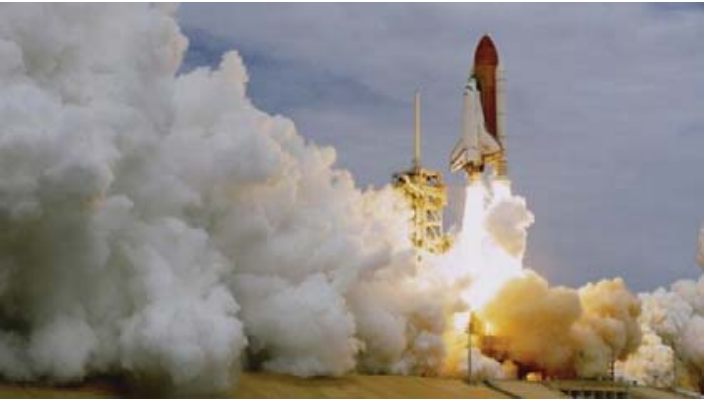

Figure 12: ARRI Alexa 120 FPS Sample Frame

\subsection{RED EPIC}

Lab tested for 11.5 stops at 0.5 stop RMS noise, LogFilm mode (HDR not yet utilized), Figure 13 .

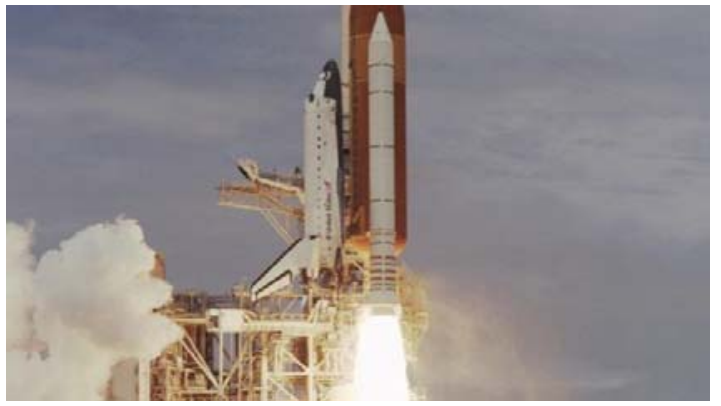

Figure 13: RED EPIC Sample Frame

\section{Conclusions}

High dynamic range is a critical capability of imaging systems for use as engineering documentation of rocket launches. Digital imaging systems that employ multiple integration times or captures have surpassed the dynamic range capability of film cameras utilized during the Space Shuttle program. The capability and usage of digital imagers requires testing and evaluation, both in a controlled lab environment as well as during actual launch events.

Current work is evaluating emerging HDR video solutions such as the RED EPIC/DRAGON with HDR setting of 6 stops, Figures 14 and 15 [Kar14], and the HDR video solution from the University of Warwick/goHDR. It is clear that future dynamic range workflows will require an examination of the entire digital process from capture to display.

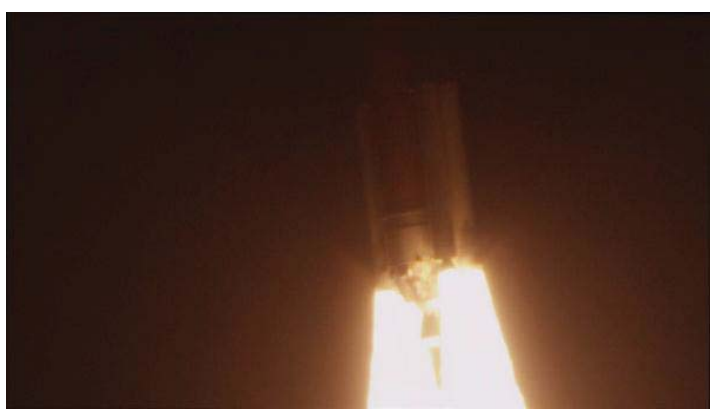

Figure 14: RED EPIC HDR 6 Mode Illustrating Dual Exposure, A Frame 


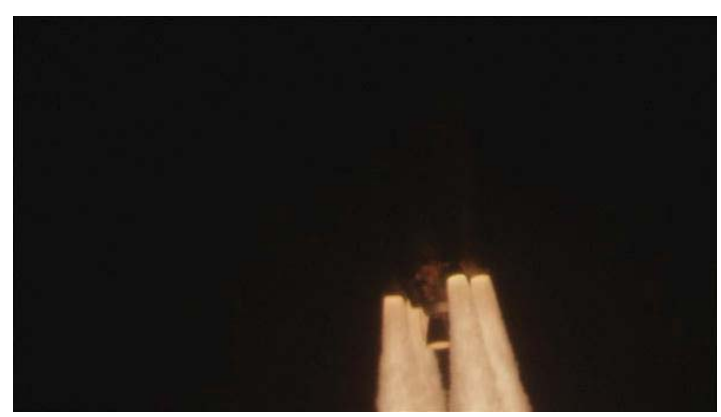

http://vimeo.com/advancedimaginglab/hdr. [Accessed 25 January 2014].

Figure 15: RED EPIC HDR 6 Mode Illustrating Dual Exposure, X Frame

\section{Acknowledgements}

Team members included Dr. Sandra Clements, Amy Elliott, Charles Harnden, Philip Haun, Brian Moravecky, Herbert Oleen, Dr. John Lane, and Omar Rodriguez. NASA Shuttle Missions sponsorship was provided by Douglas England and Robert Page. NASA sponsorship in the post-Shuttle era was provided by the Ground Systems Development and Operations (GSDO) Program, Prentice Washington and Elaine Brabaw. Additional NASA support was provided by Rodney Grubbs and Walt Lindblom of Marshall Space Flight Center (MSFC) and Larry Craig of the Launch Services Program (LSP). Additional imaging and timing support was provided by the IMCS contract. Test support provided by RED Inc., ARRI Inc., PCO AG, Photron USA, Vision Research Inc, United Launch Alliance (ULA), and Space Exploration Technologies Inc. (SpaceX).

\section{References}

[USC03] U. S. C. A. I. B. a. U. S. N. A. C. o. H Manpower, "Columbia Accident Investigation Board Report," U.S. Government Printing Office, Washington, 2003.

[NNC86] N.-N. C. Committee on Science and Technology House of Representatives, "Investigation of the Challenger Accident," US Government Printing Office, Washington, 1986.

[CHK*09] S. Clements, P. Haun, B. Karr, H. Oleen and J. Peer, "ASRC Imaging development Lab STS-129 Experimental Imagery," NASA, Kennedy Space Center, December 2009.

[CHK*10a] S. Clements, P. Haun, B. Karr and H. Oleen, "ASRC Experimental Imaging Lab STS-131Experimental Imagery," NASA, Kennedy Space Center, May 2010.

[CHK*10b] S. Clements, P. Haun, B. Karr and H. Oleen, "ASRC Experimental Imaging Lab STS-132 Experimental Imagery," NASA, Kennedy Space Center, August 2010.

[HKO11] P. Haun, B. Karr, H. Oleen and J. Lane, "Experimental Imaging Lab Activities in Support of STS-135 Launch and Landing," NASA, Kennedy Space Center, August 2011.

[Kar14] B. Karr, "Advanced Imaging Lab Vimeo Website," NASA, 2013. [Online]. Available: 
The public reporting burden for this collection of information is estimated to average 1 hour per response, including the time for reviewing instructions, searching existing

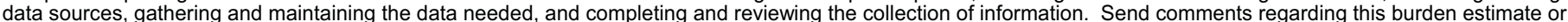

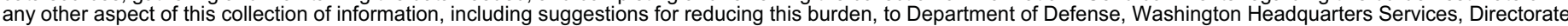

for Information Operations and Reports (0704-0188), 1215 Jefferson Davis Highway, Suite 1204, Arlington, VA 22202-4302. Respondents should be aware that

notwithstanding any other provision of law, no person shall be subject to any penalty for failing to comply with a collection of information if it does not display a currently

valid OMB control number.

PLEASE DO NOT RETURN YOUR FORM TO THE ABOVE ADDRESS
1. REPORT DATE (DD-MM-YYYY)
2. REPORT TYPE
3. DATES COVERED (From - To)

31-01-2014

Quarterly Report

October - December 2013

\section{TITLE AND SUBTITLE}

Applied Meteorology Unit (AMU) Quarterly Report

First Quarter FY-14

5a. CONTRACT NUMBER

5b. GRANT NUMBER

5c. PROGRAM ELEMENT NUMBER

\section{AUTHOR(S)}

5d. PROJECT NUMBER

William Bauman

Winifred Crawford

5e. TASK NUMBER

Leela Watson

Jaclyn Shafer

Lisa Huddleston Ryan.K.Decker

5f. WORK UNIT NUMBER

\section{PERFORMING ORGANIZATION NAME(S) AND ADDRESS(ES)}

ENSCO, Inc.

1980 N. Atlantic Ave Suite 830

Cocoa Beach, FL 32931

\section{SPONSORING/MONITORING AGENCY NAME(S) AND ADDRESS(ES)}

10. SPONSORING/MONITOR'S ACRONYM(S)

NASA

John F. Kennedy Space Center

Code GP-B

Kennedy Space Center, FL 32899

8. PERFORMING ORGANIZATION REPORT NUMBER

\section{DISTRIBUTION/AVAILABILITY STATEMENT}

Unclassified, Unlimited

\section{SUPPLEMENTARY NOTES}

\section{ABSTRACT}

This report summarizes the Applied Meteorology Unit (AMU) activities for the first quarter of Fiscal Year 2014 (October -

December 2013).

\section{SUBJECT TERMS}

Applied Meteorology Unit, Quarterly Report, Weather, Forecasting

16. SECURITY CLASSIFICATION OF:

\begin{tabular}{|l|l|l|}
\hline a. REPORT & b. ABSTRACT & c. THIS PAGE \\
$\mathrm{U}$ & $\mathrm{U}$ & $\mathrm{U}$ \\
\hline
\end{tabular}

17. LIMITATION OF ABSTRACT

UU
18. NUMBER

OF

PAGES

19
11. SPONSORING/MONITORING REPORT NUMBER 